\title{
Effects of practice schedule on the adaptive process of motor learning
}

\author{
Umberto Cesar Corrêa \\ Herbert Ugrinowitsch \\ Rodolfo Novellino Benda \\ Go Tani
}

https://doi.org/10.5628/rpcd.10.01.158
Laboratório de Comportamento Motor

Escola de Educação Física e Esporte

Universidade de São Paulo

Brazil

\begin{abstract}
This study had as objective to investigate the effects of practice schedule on the adaptive process of motor learning. The experimental design consisted of four practice groups (constant, random, constant-random and random-constant), and two learning phases (stabilization and adaptation). In three experiments, children performed a complex task of coincident timing, in which the varied practice was manipulated in terms of visual stimulus (Experiment 1), movement pattern (Experiment 2), and a combination of both (Experiment 3). In Experiment 1, the constant, constant-random, and random-constant groups showed better performance in the adaptation phase than did the random group. In Experiment 2, the constant and constantrandom groups performed better than did the others. And, in Experiment 3, the constant-random group demonstrated better performance than the others. Overall results indicated that, during the adaptive process of motor skill acquisition, constant and constant-random practice, were superior to random and random-constant practice.
\end{abstract}

Key-words: practice schedule, motor learning, adaptive process, non-equilibrium model

\section{RESUMO}

Efeitos da estrutura de prática sobre o processo adaptativo de aprendizagem motora

Este estudo teve como objetivo investigar os efeitos da estrutura de prática no processo adaptativo de aprendizagem motora. $O$ delineamento constou de quatro grupos de prática (constante, aleatória, constante-aleatória e aleatória-constante) e de duas fases de aprendizagem (estabilização e adaptação). Nos três experimentos crianças praticaram uma tarefa complexa de timing coincidente, na qual a prática variada foi manipulada em termos de estímulo visual (Experimento 1), padrão de movimento (Experimento 2) e ambos os aspectos (Experimento 3). No experimento 1 , os grupos constante, constante-aleatória e aleatória-constante mostraram melhor desempenho na fase de adaptação do que o grupo de prática aleatória. No experimento 2, os grupos constante e constant-aleatória tiveram melhor performance do que os demais. E, no experimento 3, o grupo constante-aleatória foi aquele com melhor desempenho. No seu conjunto, os resultados indicaram que as práticas constante e constante-aleatória foram superiores no processo adaptativo de aprendizagem motora do que as práticas aleatória e aleatória-constante

Palavras-chave: estrutura de prática, aprendizagem motora, processo adaptativo, modelo de não-equilíbrio 


\section{INTRODUCTION}

All living organisms are essentially an open system, because they maintain themselves in a continuous exchange of matter and information, conserving themselves in the presence of the building and decomposition of components. Whilst alive, they never reach a state of thermodynamic equilibrium, but instead remain in a so-called "dynamically irreversible steady state," or an almost stationary state(4). When open systems interact with the environment, which itself is constantly changing, they face disturbances that can challenge their stability. How do open systems respond to such perturbations? The two basic possibilities are: a) maintaining stability by eliminating the perturbation through self-regulatory mechanisms, relying on negative feedback to maintain structure; b) using the perturbation as a source for reorganization in an attempt to reach a new regime of stability. In living systems, the capacity to undergo changes toward new states of organization is a fundamental property $(10,20,21)$.

Motor learning theories describe skill acquisition as a process, unfolding in phases, in which initial inconsistencies and lack of coordination in movement are gradually eliminated, and are replaced by patterned and accurate movements ${ }^{(2,29)}$. The final phase of this process is known as automatization, characteristically a stabilization phenomenon. Since humans are open systems, motor learning theories should provide explanations about how new skills emerge from old ones. Therefore, new theoretical models must be proposed that can overcome the limitations of equilibrium-oriented theories and explain the process of motor learning beyond the level of stabilization.

Current theories of motor learning $(1,32)$ are concerned with the process of stabilization of performance, the homeostatic process. These equilibriumoriented theories rely upon negative feedback (process of diminishing discrepancies/errors) and, therefore, are limited in their ability to explain the complex processes involved in the acquisition of motor skills(18). Processes that rely upon negative feedback can help explain the maintenance of a structure, or an order in which certain developments occur, but they cannot help to explain the emergence of a new structure, because generating new structures requires a breakdown of stability ${ }^{(31)}$.
In an attempt to explain motor skill acquisition beyond stabilization, a non-equilibrium model of motor learning has been proposed $(6,7,8,36,37,38)$. This model regards motor learning as a two-process phenomenon: stabilization and adaptive. During the stabilization process, initially inconsistent and incorrect responses are gradually reduced by a negative feedback mechanism. As a result, functional stabilization is achieved and includes the formation of a structure. Automatization is typically a stabilization phenomenon.

Once stabilized, the system typically is challenged by a perturbation (new environment demands or new goals), and it tries to adapt. The adaptive process refers to the formation of others structures that are based on those which currently exist, through breaks in stability. Each adaptation to stability is then followed by another, reflecting adaptations to new situations or motor tasks, and based on previously acquired skills. In some cases, adaptation can occur after the modification of a parameter through the flexibility of the system itself. However, other disturbances demand modifications to the structure of existing skills, requiring a reorganization of the structure itself or the emergence of a completely new structure. This latter type of adaptation is known as self-organizational.

Generally, studies on motor skill learning have used experimental design with acquisition phase plus transfer test. In this type of design the focus is on stabilization of performance and the transfer test is used to access the transfer of functions $(11,15,34)$. No attention is given on transfer of structure. On the other hand, adaptive process has being seen as a phase of motor learning. Adaptive process is a problem of changes in motor skill structures.

It should be noted that motor skills are essential to humans (open systems), since they are the means by which individuals interact with their environments ${ }^{(9)}$. There is a general consensus that, independent of the approach used to study the learning of motor skills, it relies upon acquired behaviors in which practice is a fundamental element ${ }^{(33)}$. For this reason, the effects of practice schedules have been investigated, with a special focus on constant and variable practice $(12,13)$. In the first study(12), which included two phases: stabilization and adaptation, thirty-nine children of both sexes were distributed 
into four experimental groups: constant practice, random practice, constant-random practice, and random-constant practice. During the stabilization phase, the distance between the origin of throw and the target was manipulated. In the adaptation phase, the distance between the origin of throw and the target, and the type of throwing was modified. The results showed similar effects for all groups in both phases of the experiment. In the second study(13), eighty subjects, male and female, voluntarily participated in an experiment that utilized the same design as the first in terms of groups (constant practice, random practice, constant-random practice, and random-constant practice) and experimental phases (stabilization and adaptation). In the learning task, however, participants manipulated the manual force control of a digital handgrip dynamometer in order to reach pre-established performance goals. The results in the adaptation phase showed higher performance levels in the constant and constant-random practice groups in relation to the other groups. In the overall literature, results are not conclusive; although it appears that the specificity of the task plays an important role in this context. In both studies $(12,13)$ the tasks and measures were limited to show how adaptation took place. In fact, type of task has long been a crucial aspect in model and theory construction throughout the field of motor control and learning $(28,29)$. Therefore, this study employed a complex coincident timing task that was composed of a sequence of actions, resulting from of an external stimulus: a task with high perceptual and motor demands. Moreover, the instrument enabled performance measurements (absolute and variable errors) and measurements pertaining to the pattern of execution (movement time, relative timing). The notion of varied practice has provided the basis for numerous studies as well as an ongoing debate about when and how to vary it $(5,22,26)$. Thus, the variability of practice could be manipulated in terms of perceptual aspects (Experiment 1), motor aspects (Experiment 2), and a combination of both (Experiment 3 ).

\section{EXPERIMENT 1}

\section{Subjects}

Fifty-eight children who had not formerly performed the experimental task, both male $(n=29)$ and female $(n=29)$, with an average age of 12.2 years $( \pm 0.9)$, voluntarily participated in this experiment. Parental consent was obtained by school administrators of the school in which the study was carried out. Children in this age range were chosen as participants instead of adults in order to reduce the "experience effect," but, also, because they were old enough to be able to perform the experimental task ${ }^{(3)}$.

\section{Instrument and task}

A custom-designed "Coincident Timing in Complex Tasks" device was employed (Figure 1). This apparatus enabled the execution of a complex task, composed of a sequence of actions that were carried out as a result of an external stimulus: a task with high perceptual and motor skill demands. Additionally, the instrument enabled performance measurements (absolute and variable errors) and measurements that pertained to the pattern of execution (movement time and relative timing).

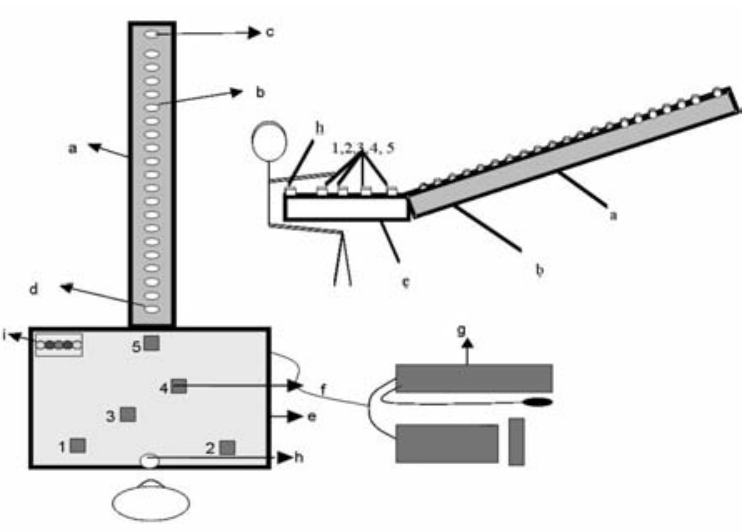

Figure 1. Illustration of apparatus for measuring coincident timing in complex tasks: a] wooden box, b] LEDs, c] alert $L E D, d$ ) target lead, e] wooden table, $f$ ] touch sensor, $g$ ] computer, $h$ ] place of positioning for the execution hand, i) visual feedback.

The device was composed of a wooden box, 200 centimeters long, 10 centimeters wide and 10 centimeters high, which was supported in front of a wooden table. Ninety LEDs (Light-emitting diodes) were placed in a row beneath the cover plate, 1 centimeter apart. Five targets were placed on the $70 \mathrm{~cm} \times 90 \mathrm{~cm}$ x $6 \mathrm{~cm}$ wooden table, $5 \mathrm{~cm}$ apart, at $15 \mathrm{~cm}$ intervals. Custom software allowed the LEDs to be switched on and off in sequence, at different speeds, and with 
Table 1. Design of experiment 1.

\begin{tabular}{llll}
\hline $\begin{array}{l}\text { Phases } \\
\text { Groups }\end{array}$ & $\begin{array}{l}\text { Stabilization } \\
\text { [72 trials }\end{array}$ & & $\begin{array}{c}\text { Adaptation } \\
\text { [36 trials] }\end{array}$ \\
\hline Constant & $142.2 \mathrm{~cm} / \mathrm{s}$ & $104,9 \mathrm{~cm} / \mathrm{s}$ \\
\hline Random & $142.2 \mathrm{~cm} / \mathrm{s}, 165.7 \mathrm{~cm} / \mathrm{s}, 124.5 \mathrm{~cm} / \mathrm{s}$ & $104,9 \mathrm{~cm} / \mathrm{s}$ \\
\hline Constant-Random & $142.2 \mathrm{~cm} / \mathrm{s}$ & $142.2 \mathrm{~cm} / \mathrm{s}, 165.7 \mathrm{~cm} / \mathrm{s}, 124.5 \mathrm{~cm} / \mathrm{s}$ & $104,9 \mathrm{~cm} / \mathrm{s}$ \\
\hline Random-Constant & $142.2 \mathrm{~cm} / \mathrm{s}, 165.7 \mathrm{~cm} / \mathrm{s}, 124.5 \mathrm{~cm} / \mathrm{s}$ & $104,9 \mathrm{~cm} / \mathrm{s}$ & $104,9 \mathrm{~cm} / \mathrm{s}$ \\
\hline
\end{tabular}

varying acceleration. The computer recorded the following values: the execution time of the task $(1 \rightarrow 5)$; the time of each component, or rather, the partial times $(1 \rightarrow 2,2 \rightarrow 3,3 \rightarrow 4,4 \rightarrow 5)$; the coincident timing, which pertained to the time between the last touch and activation of the target LED ( $5 \rightarrow$ target LED). The task required the participant to touch with the preferred hand five sensors in a sequence in such a way that the last touch would coincide with the activation of a target LED.

\section{Design and procedures}

In this experiment, the varied practice was manipulated in terms of different visual stimulus speeds. Seventy-two trials were carried out during the stabilization phase, according to the experimental condition of each group. The adaptation phase, which included 36 trials, was carried out in the same condition for all groups, but different from the previous phase. All groups performed the task in both phases of the experiment, touching the sensors in the order described above.

The design included the following practice groups: constant ( $n=15,7$ boys and 8 girls), random $(n=14$, 7 boys and 7 girls), constant-random ( $n=15,8$ boys and 7 girls), and random-constant ( $n=14,7$ boys and 7 girls). In the stabilization phase, the participants from the constant group performed all of the trials in which the visual stimulus did not vary from a single speed $(\mathrm{V} 1=142.2 \mathrm{~cm} / \mathrm{s})$. Participants from the random group performed all of the trials in which the visual stimulus randomly varied at three speeds $(\mathrm{V} 1=142.2 \mathrm{~cm} / \mathrm{s}, \mathrm{V} 2=165.7 \mathrm{~cm} / \mathrm{s}$, and $\mathrm{V} 3=124.5 \mathrm{~cm} / \mathrm{s}$ ). Participants from the constantrandom group performed the first half of the trials in the same manner as the constant group (V1), and the subsequent trials at the three speeds of the stimulus (V1, V2, and V3) randomly, or rather, similar to the random group; the volunteers from the randomconstant group performed the first half of the trials randomly varying the speed of the stimulus (V1, V2, and V3), and the subsequent trials in a single speed (V1). In the adaptation phase, all of the groups executed the trials at the same speed as the visual stimulus (V4=104,9 cm/s), unlike those practiced in the stabilization phase.

The inter-trial interval was approximately 8 seconds, and the interval between phases was approximately 60 seconds. Instrument provided visual feedback after each trial, which informed the error in terms of magnitude and direction.

The experiments took place in a public school, in a closed, $4 \mathrm{~m} \times 5 \mathrm{~m}$ room. The experimenter seated each participant in an adjustable chair in front of the test device, with their abdomens at table height, so that he or she could freely reach all of the sensors. Each also was tested to make certain that he or she could touch the targets without having to stretch over the table. Once these requirements were met, the experimenter explained to the participant how to work the device and complete the required task. Afterwards, the experimenter checked with each participant to be sure that he or she understood the task, which would require them to execute the touch sequence as many as five times.

\section{Data treatment}

Performance was measured through the precision and consistency of coincident timing, absolute error, and variable error, respectively. Measurements pertaining to the movement pattern also were used (relative timing and total movement time). Relative tim- 

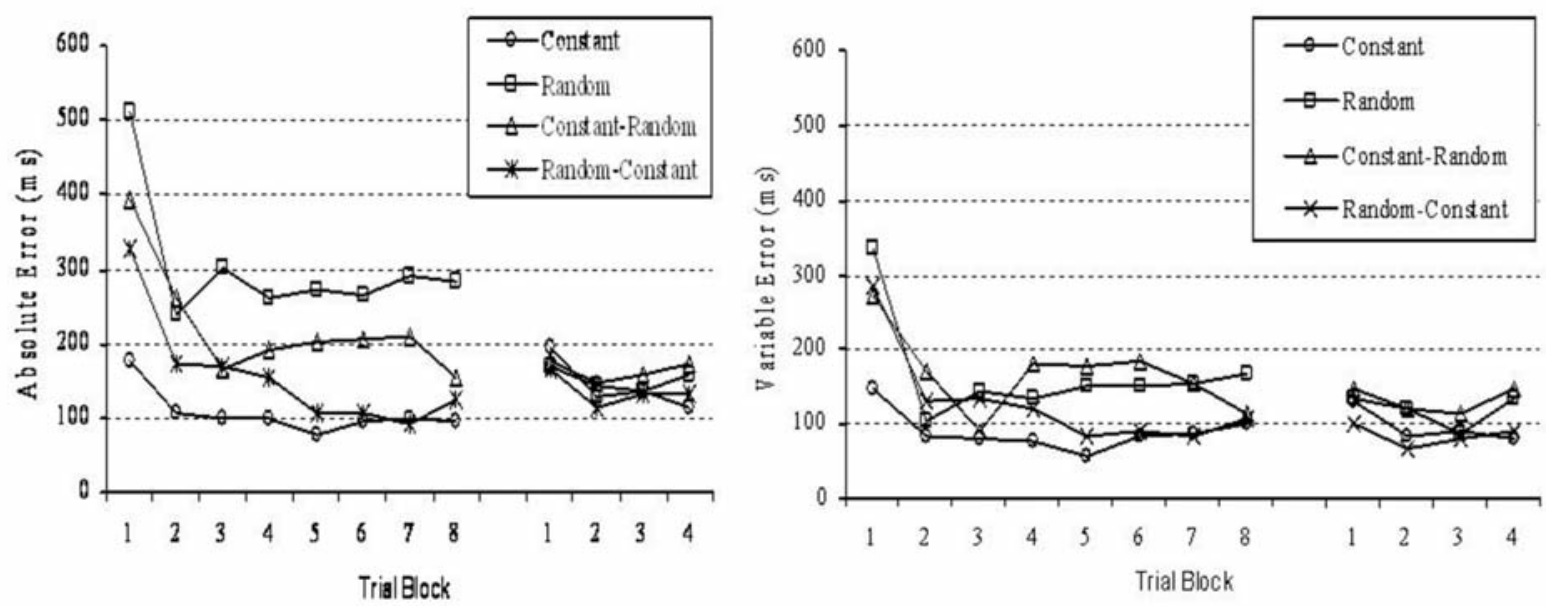

Figure 2. Mean of absolute and variable errors (ms] in blocks of nine trials, in the stabilization [1 through 8] and adaptation [1 through 4 ] phases, Experiment 1.

ing of the five components (touches) was utilized to access invariant aspects of the movement pattern. Movement time was used to access variable aspects of the movement pattern through standard deviation. Absolute and variable errors and overall movement patterns were analyzed through ANOVAS. In the stabilization phase, an ANOVA (one-way) was conducted for each group in order to verify the behavior of each group in the experimental situation. In the adaptation phase, a two-way ANOVA (4 groups $\mathrm{x} 4$ blocks), with repeated measures in the second factor, was conducted in order to compare the effects of independent intra- and inter-groups. For each group the magnitude of the relative timing was analyzed by MANOVA, followed by a univariate test of significance. In this case, the behavior of the components in the last blocks of trials from the stabilization phase, and the first block of the adaptation phase, was analyzed in order to verify how the adaptation took place. In all analyses the TukeyHSD post-hoc test was used.

\section{RESULTS}

\section{Absolute and variable errors}

In the stabilization phase, all of the groups decreased their absolute error: constant $\mathrm{F}_{7,112}=5.14$, $\mathrm{p}<0.01$; constant-random $\mathrm{F}_{7,112}=1.98, \mathrm{p}<0.05$; random-constant $\mathrm{F}_{7,104}=11.28, \mathrm{p}<0.01$; and random
$\mathrm{F}_{7,104}=1.12, \mathrm{p}>0.05$. In the adaptation phase, effects were found only for blocks: $F_{3,162}=6.65, p<0.01$. Similar to the previous measurement, all of the groups decreased the variable error in the stabilization phase: constant $\mathrm{F}_{7,112}=2.81, \mathrm{p}<0.01$; random $\mathrm{F}_{7,104}=10.85, \mathrm{p}<0.01$; constant-random $\mathrm{F}_{7,112}=2.33$, $\mathrm{p}<0.05$; and random-constant $\mathrm{F}_{7,104}=5.64, \mathrm{p}<0.01$. However, an ANOVA did not show any effect in the adaptation phase.

\section{Movement pattern}

The multivariate tests did not reveal differences in the relative timing for the constant, constant-random, and random-constant groups. For the random group, results included: Wilks' Lambda $=0.16$, Rao's $_{5,9}=9.29, p=0.00$. Unvaried analysis showed differences in the second and fifth components. With regard to movement time, during the stabilization phase, it was observed that all of the groups decreased in variability. The ANOVAS revealed: $\mathrm{F}_{7,98}=2.37, \mathrm{p}<0.05$ for the constant group; $\mathrm{F}_{7,91}=6.56, \mathrm{p}<0.01$ for the random group; $\mathrm{F}_{7,98}=4.13, \mathrm{p}<0.01$ for the constant-random group; and $\mathrm{F}_{7,91}=5.00 \mathrm{p}<0.01$ for random-constant group. In the adaptation phase, effects were found only for blocks, $\mathrm{F}_{4,216}=2.79, \mathrm{p}<0.05$, showing a decrease in the movement time variability from the second to the third blocks of trials. 
(a)

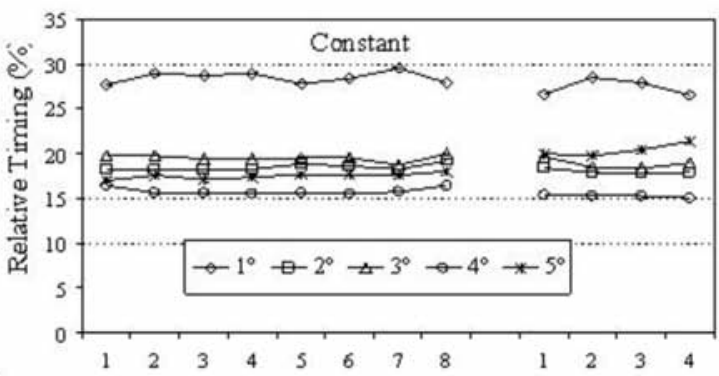

Trial Block
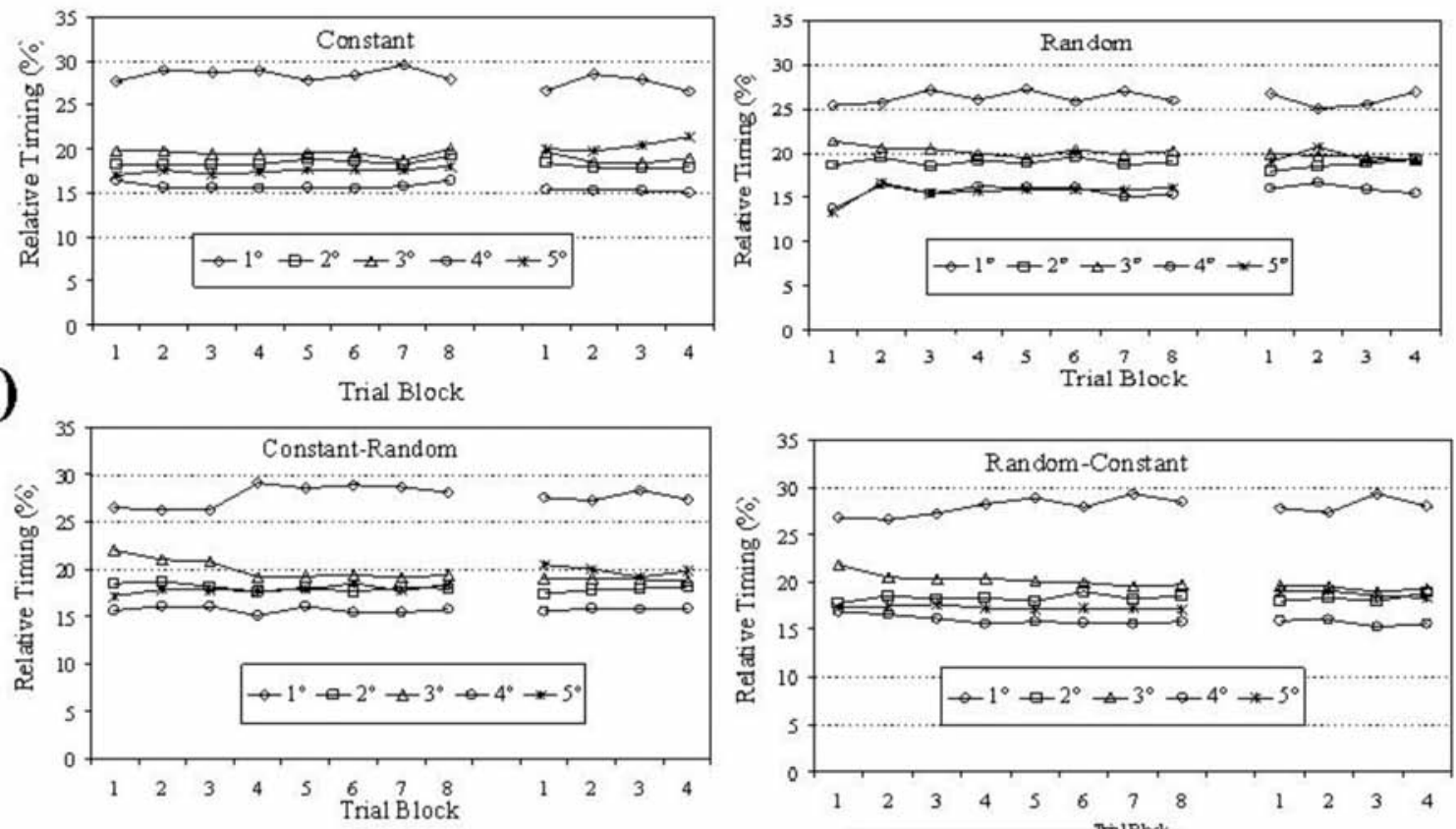

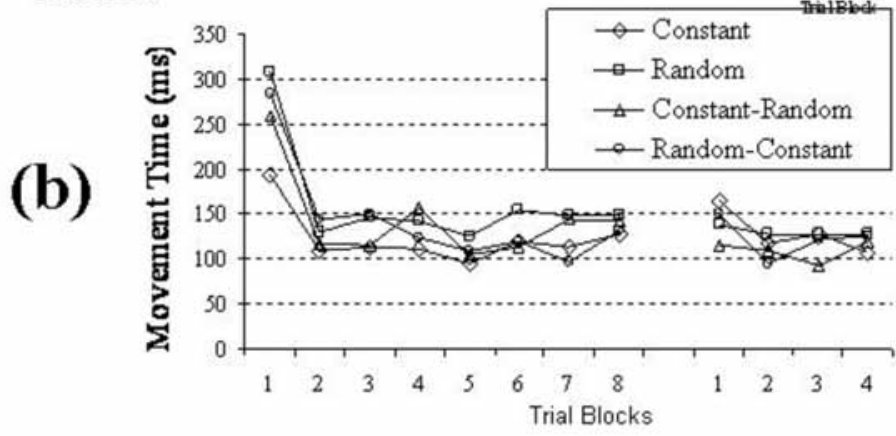

Figure 3. Movement pattern results in blocks of nine trials, in the stabilization (1 through 8) and adaptation (1 through 4) phases, Experiment 1: (a) mean of the magnitude of relative timing (\%) of each component $\left[1^{\circ}, 2^{\circ}, 3^{\circ}, 4^{\circ}\right.$, and $5^{\circ}$ ); (b) mean of variability of movement time (ms).

\section{DISCUSSION}

The initial results of this experiment indicated that the constant and random practices, plus their combinations, had similar effects on the adaptive process, since all of the groups maintained the same levels of performance (absolute and variable errors).

However, the results for movement patterns suggested that adaptation differed between the groups. Constant practice, allied with random practice, contributed to the formation of a more flexible structure than did random practice only. This is likely due to the fact that subjects from the constant, constant-ran- dom, and random-constant practice groups adapted themselves without any modification of the movement pattern structure; and random practice group subjects adapted themselves via the modification of relative timing ( $2^{\text {nd }}$ and $5^{\text {th }}$ components). Thus, it can be assumed that for the groups which had constant practice, modification of the perceptual aspect of the task (speed of the visual stimulus) could be predicted by the individual (the "system"), making "passive" adaptation possible: that which was carried out through the flexibility of the system itself $(16,36)$. 
Table 2. Design of experiment 2.

\begin{tabular}{|c|c|c|c|}
\hline $\begin{array}{l}\text { Phases } \\
\text { Groups } \boldsymbol{\nabla}\end{array}$ & \multicolumn{2}{|l|}{$\begin{array}{l}\text { Stabilization } \\
\text { [72 trials] }\end{array}$} & $\begin{array}{l}\text { Adaptation } \\
\text { [36 trials] }\end{array}$ \\
\hline Constant & \multicolumn{2}{|l|}{ SQ1 } & SQ4 \\
\hline Random & \multicolumn{2}{|l|}{ SQ1, SQ2, SQ3 } & SQ4 \\
\hline Constant-Random & SQ1 & SQ1, SQ2, SQ3 & SQ4 \\
\hline Random-constant & SQ1, SQ2, SQ3 & SQ1 & SQ4 \\
\hline
\end{tabular}

\section{EXPERIMENT 2}

\section{Participants}

Participants were similar to those in the previous experiment. Fifty-four children, male $(n=27)$ and female $(n=27)$, with an average age of 12.2 years $( \pm 1.0)$, without prior experience performing the experimental task, volunteered to participate in this experiment. They were randomly distributed into four experimental practice groups: constant $(n=16$, 8 boys and 8 girls), random ( $n=12,6$ boys and 6 girls), constant-random ( $\mathrm{n}=12,6$ boys and 6 girls), and random-constant ( $\mathrm{n}=14,7$ boys and 7 girls).

\section{Instrument, task, design, procedures and data treatment} These aspects, also, were similar to those in Experiment 1. In this experiment, however, all of the groups executed the task at the same speed as the visual stimulus $(\mathrm{V} 1=142.2 \mathrm{~cm} / \mathrm{s})$ during both phases of the experiment. The varied practice involved the manipulation of different response patterns: that is, different target touching sequences. Unlike Experiment 1, in which varied practice was one of the perceptual aspects of the task, Experiment 2 included variability as it was related to movement patterns (Table 2).

In the stabilization phase, individuals in the constant group performed all of the trials utilizing a single target touching sequence (SQ1=1-2-4-3-5) (see Figure 1). Individuals in the random group performed all of the trials employing a random variation of three target touching sequences ( $\mathrm{SQ} 1=1-2-4-3-5$, SQ2 $=1-3-2-4-5$, and SQ3 $=1-4-2-3-5)$. The constantrandom group individuals performed the first half of the trials (36 trials) just as did the constant group individuals (SQ1); the following 36 trials included the three different target touching sequences (SQ1, SQ2, and SQ3), performed randomly. The individuals in the random-constant group performed the first half of the trials randomly, varying target touching sequences (SQ1, SQ2, and SQ3), and the second half of the trials using a single target touching sequence (SQ1). In the adaptation phase, all of the groups executed the trials using a single target touching sequence (SQ4=1-4-3-2-5), different from those utilized during the stabilization phase.

\section{RESULTS}

\section{Absolute and variable errors}

In the stabilization phase, with the exception of the constant-random group, all of the groups decreased their absolute error. The ANOVAs included the following values: $\mathrm{F}_{7,120}=5.76$, and $\mathrm{p}<0.01$, for the constant group; $\mathrm{F}_{7,88}=7.81$, and $\mathrm{p}<0.01$, for the random group; and $\mathrm{F}_{7,112}=3.87$, and $\mathrm{p}<0.01$ for the randomconstant group. In the adaptation phase, effects were found for groups: $\mathrm{F}_{3,50}=3.94, \mathrm{p}<0.01$ ); and blocks: $\mathrm{F}_{3,150}=15.26, \mathrm{p}<0.00$, revealing superior performances for the constant and constant-random practice groups. With regard to blocks, post-hoc tests indicated that absolute error decreased significantly in this phase.

Regarding variable error, differences were found for the constant, $\mathrm{F}_{7,120}=5.12, \mathrm{p}<0.01$, random $\mathrm{F}_{7,88}=4.21, \mathrm{p}<0.01$, and random-constant groups $\mathrm{F}_{7,112}=2.19, \mathrm{p}<0.05$. For the adaptation phase, the two-way ANOVA revealed effects only for blocks, $\mathrm{F}_{3,147}=7.33, \mathrm{p}<0.01$. 

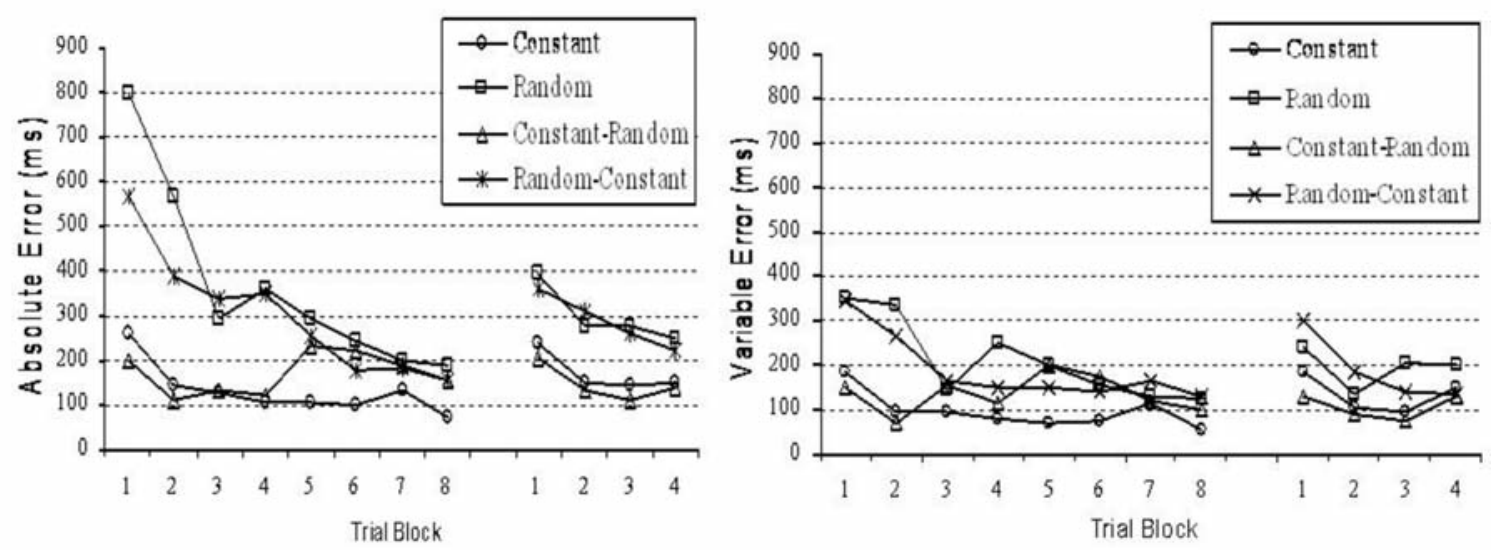

Figure 4. Mean of absolute and variable errors (ms) in blocks of nine trials, in the stabilization (1 through 8) and adaptation (1 through 4) phases, Experiment 2.

(a)

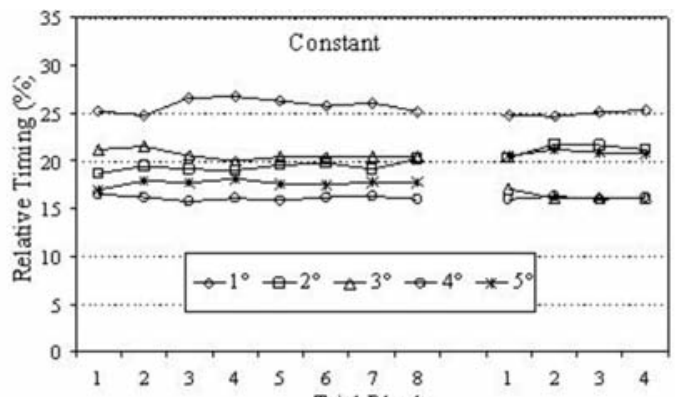

Trial Block
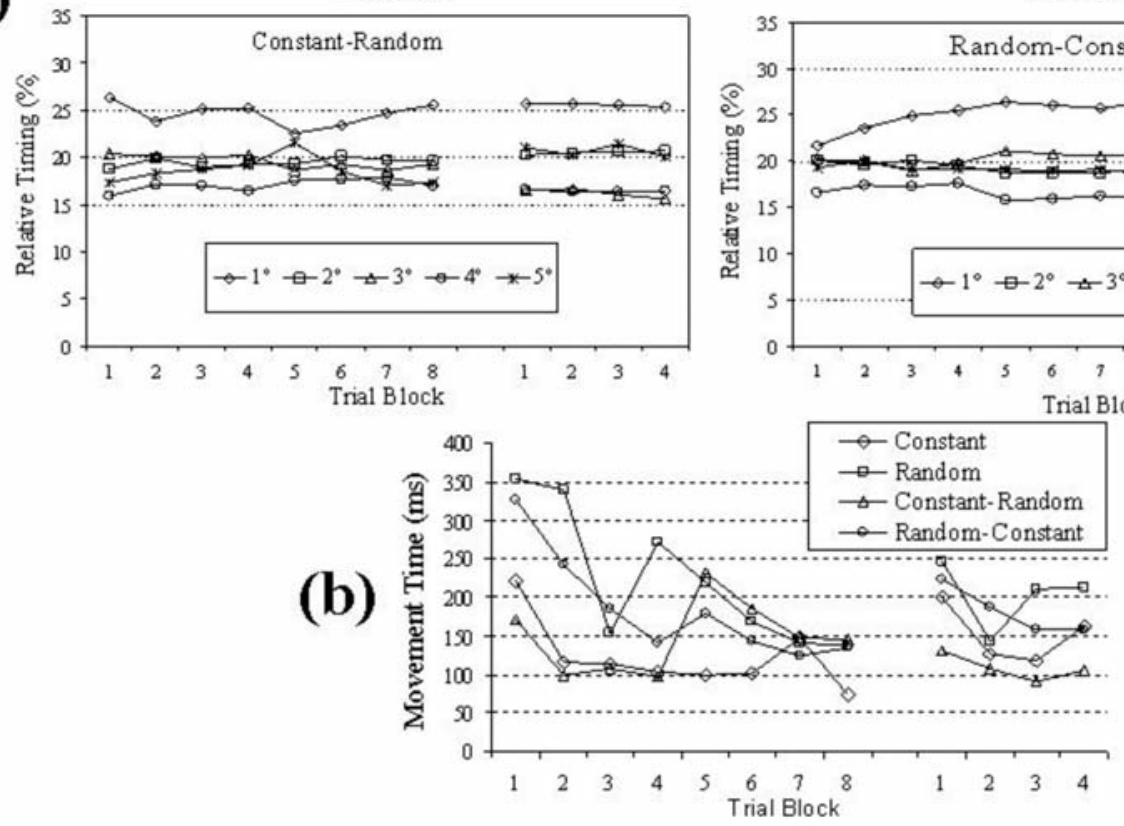

Figure 5. Movement pattern results in blocks of nine trials, in the stabilization (1 through 8) and adaptation (1 through 4) phases, Experiment 2: (a) mean of the magnitude of relative timing (\%) of each component $\left[1^{\circ}, 2^{\circ}, 3^{\circ}, 4^{\circ}\right.$, and $\left.5^{\circ}\right)$; (b) mean of variability of movement time (ms]. 


\section{Movement pattern}

The multivariate tests found differences for relative timing of the constant group: Wilks' Lambda $=0.06$, Rao's $_{5,11}=35.70, \mathrm{p}<0.01$; and for constant-random groups: Wilks' Lambda $=0.12$, Rao's ${ }_{5,6}=8.99, \mathrm{p}<0.01$. For both, the unvaried analysis showed differences with regard to the third and fifth components. Differences were found for the other groups as well. In terms of movement time, it was observed that in the stabilization phase, only the constant-random group did not decrease variability. For the others groups, ANOVAs revealed $\mathrm{F}_{7,105}=8.49, \mathrm{p}<0.01$, $\mathrm{F}_{7,77}=5.27, \mathrm{p}<0.01$, and $\mathrm{F}_{7,84}=4.07, \mathrm{p}<0.01$, respectively, for the constant, random, and random-constant groups. For the adaptation phase, the ANOVA (two-way) revealed effect only for blocks: $F_{4,19}=5.17$, $\mathrm{p}<0.01$. The TukeyHSD test indicated that the movement variability time increased in the last block of trials from the stabilization phase to the first block of the adaptation phase, and that it decreased in the two following blocks.

\section{DISCUSSION}

These results imply greater adaptation for the constant and constant-random practice groups. We suggest that these groups performed better than did the random and random-constant groups in terms of errors because they were able to modify the movement pattern's invariant structure (relative timing) with regard to two components ( $3^{\text {rd }}$ and $5^{\text {th }}$ ) in order to adapt to disturbances. The random and randomconstant practice groups did not make these modifi- cations. What was also verified is that modification of the task disturbed the respective aspect's variants of movement pattern equally in all groups. It is, therefore, possible to conclude that individuals in the constant and constant-random practice groups became sufficiently competent to change their invariant structure of the movement pattern so that they were able to manage the disturbance.

\section{EXPERIMENT 3}

\section{Participants}

The subjects were similar to those in the previous two experiments. Forty-seven children, male $(n=24)$ and female $(n=23)$, with an average age of 12.7 years $( \pm 0.9)$, without experience in the acquisition phase testing, were randomly distributed into four experimental groups: constant $(n=12,6$ boys and 6 girls), random ( $n=12,6$ boys and 6 girls), constantrandom ( $n=12,6$ boys and 6 girls), and randomconstant ( $n=11,6$ boys and 5 girls).

Instrument, task, design, procedures, and data treatment Similar to Experiments 1 and 2, in Experiment 3 varied practice was manipulated in terms of visual stimulus and movement patterns (Table 3 ). In the stabilization phase, participants from the constant group executed all of the trials at a single visual stimulus speed while performing the sensor touch sequence $(\mathrm{V} 1=142.2 \mathrm{~cm} / \mathrm{s} ; \mathrm{SQ} 1=1-2-4-3-5)$. The children from the random group executed all of the trials combining three different speeds and sequences, randomly $(\mathrm{V} 1=142.2 \mathrm{~cm} / \mathrm{s}, \mathrm{V} 2=165.7$

Table 3. Design of experiment 3

\begin{tabular}{|c|c|c|c|}
\hline $\begin{array}{l}\text { Phases } \\
\text { Groups } \nabla\end{array}$ & \multicolumn{2}{|l|}{$\begin{array}{l}\text { Stabilization } \\
\text { [72 trials] }\end{array}$} & $\begin{array}{l}\text { Adaptation } \\
\text { (36 trials) }\end{array}$ \\
\hline Constant & \multicolumn{2}{|l|}{$\mathrm{V} 1 / \mathrm{SQ} 1$} & V4/SQ4 \\
\hline Random & \multicolumn{2}{|c|}{ V1/SQ1, V1/SQ2, V1/SQ3, V2/SQ1, V2/SQ2, V2/SQ3, V3/SQ1, V3/SQ2, V3/SQ3 } & V4/SQ4 \\
\hline Constant-Random & V1/SQ1 & $\begin{array}{l}\text { V1/SQ1, V1/SQ2, V1/SQ3, } \\
\text { V2/SQ1, V2/SQ2, V2/SQ3, } \\
\text { V3/SQ1, V3/SQ2, V3/SQ3 }\end{array}$ & V4/SQ4 \\
\hline Random-Constant & $\begin{array}{l}\text { V1/SQ1, V1/SQ2, V1/SQ3, } \\
\text { V2/SQ1, V2/SQ2, V2/SQ3, } \\
\text { V3/SQ1, V3/SQ2, V3/SQ3 }\end{array}$ & V1/SQ1 & V4/SQ4 \\
\hline
\end{tabular}


$\mathrm{cm} / \mathrm{s} ., \mathrm{V} 3=124.5 \mathrm{~cm} / \mathrm{s}$; SQ1 $=1-2-4-3-5$, SQ2 $=1-3-2-$ $4-5$, SQ3 =1-4-2-3-5). The individuals from the constant-random group performed the first half of the trials in the same manner as did those from the constant group (V1 - SQ1), and the second half as did the children in the previous trials in the random group (V1, V2, V3; SQ1, SQ2, SQ3). Lastly, the participants from the random-constant group performed the first half of the trials while randomly varying the touch order and the stimulus speed (V1, V2, V3; SQ1, SQ2, SQ3), and the remaining trials at a single speed and touch sequence (V1; SQ1).

In the adaptation phase, all of the groups executed the trials using a single touch and equal stimulus speed (V4=104.9 cm/s; SQ4=1-4-3-2-5), different from those practiced in the stabilization phase.

\section{RESULTS}

\section{Absolute and variable errors}

In the stabilization phase all of the groups decreased their absolute error. The one-way ANOVA revealed: $\mathrm{F}_{7,77}=4.92, \mathrm{p}<0.01$ for constant; $\mathrm{F}_{7,77}=3.19, \mathrm{p}<0.01$ for random; $\mathrm{F}_{7,77}=7.27, \mathrm{p}<0.01$ for constant-random; and $\mathrm{F}_{5,70}=9.53, \mathrm{p}<0.01$ for random-constant groups. With regard to the results of the adaptation phase, the ANOVA (two-way) showed differences between groups: $\mathrm{F}_{3,43}=2.92, \mathrm{p}<0.05$, and blocks: $\mathrm{F}_{3,129}=9.90, \mathrm{p}<0.00$. In relation to the differences between groups, the TukeyHSD test showed better performance for constant-random than random-con- stant group. Concerning blocks differences, it was verified better performance in the first block in relation to the others.

With regard to the variable error, in the stabilization phase, only the random group did not decrease it. Results in the random-constant group included: $\mathrm{F}_{7,70}=3.66, \mathrm{p}<0.01$; in the constant-random group: $\mathrm{F}_{7,77}=4.76, \mathrm{p}<0.01$, and in the constant group: $\mathrm{F}_{7,77}=4.81, \mathrm{p}<0.01$. In relation to the adaptation phase, the two-way ANOVA found $F_{3,43}=3.35$, $\mathrm{p}<0.05$ for groups. Thus, the performance of the constant-random group was superior to that of the random-constant group.

\section{Movement pattern}

The multivariate tests showed that all groups adapted by modifying some aspect of their invariant structure. For the constant group, MANOVA analysis revealed these results: Wilks' Lambda $=0.15$, Rao's $_{5,7}=7.89, \mathrm{p}<0.01$; for the random group: Wilks' Lambda $=0.09$, Rao's ${ }_{5,7}=13.37, \mathrm{p}<0.00$; for the constant-random group: Wilks' Lambda $=0.17$, Rao's $_{5,7}=7.01, \mathrm{p}<0.01$; and, for the random-constant group: Wilks' Lambda $=0.20$, Rao's $s_{5,6}=4.90, \mathrm{p}=0.04$. It was verified that the constant group modified the first, third, and fifth components; the random group modified the third, fourth, and fifth components; the constant-random group modified the fourth and fifth components; and, the random-constant group modified the second, third, and fifth components.
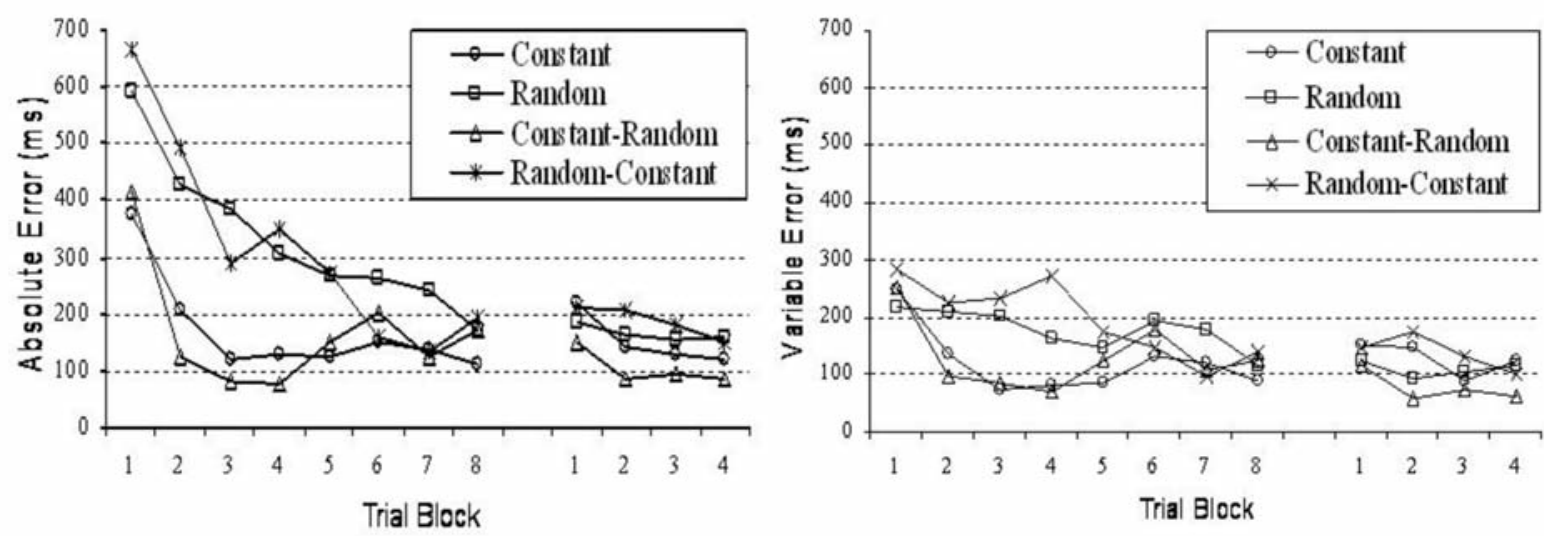

Figure 6. Mean of absolute and variable errors ( $\mathrm{ms}$ ) in blocks of nine trials, in the stabilization (1 through 8) and adaptation (1 through 4 ] phases, Experiment 3. 

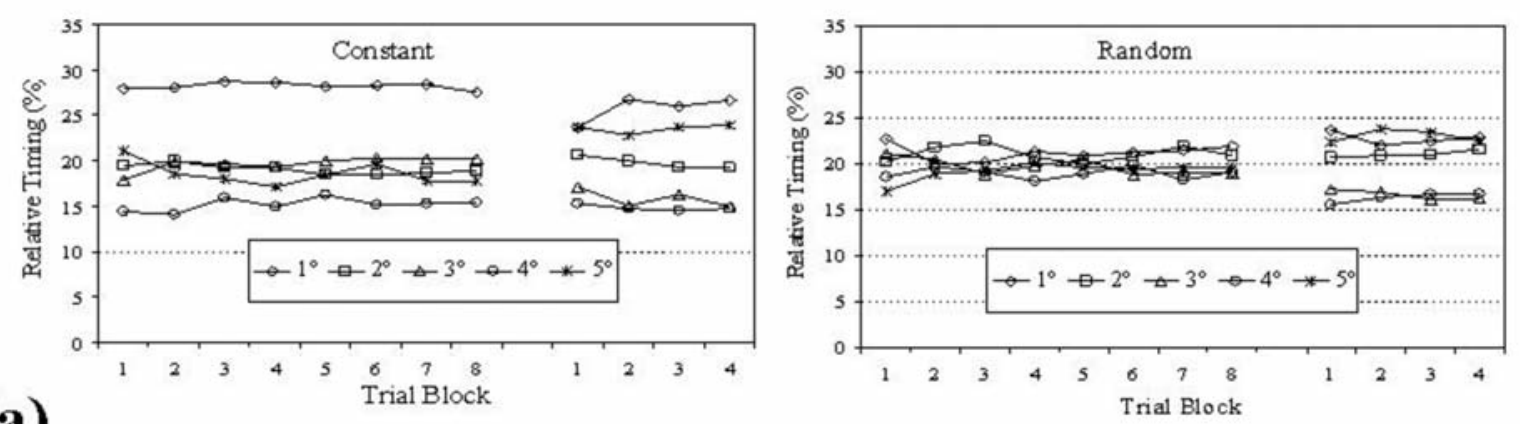

(a)
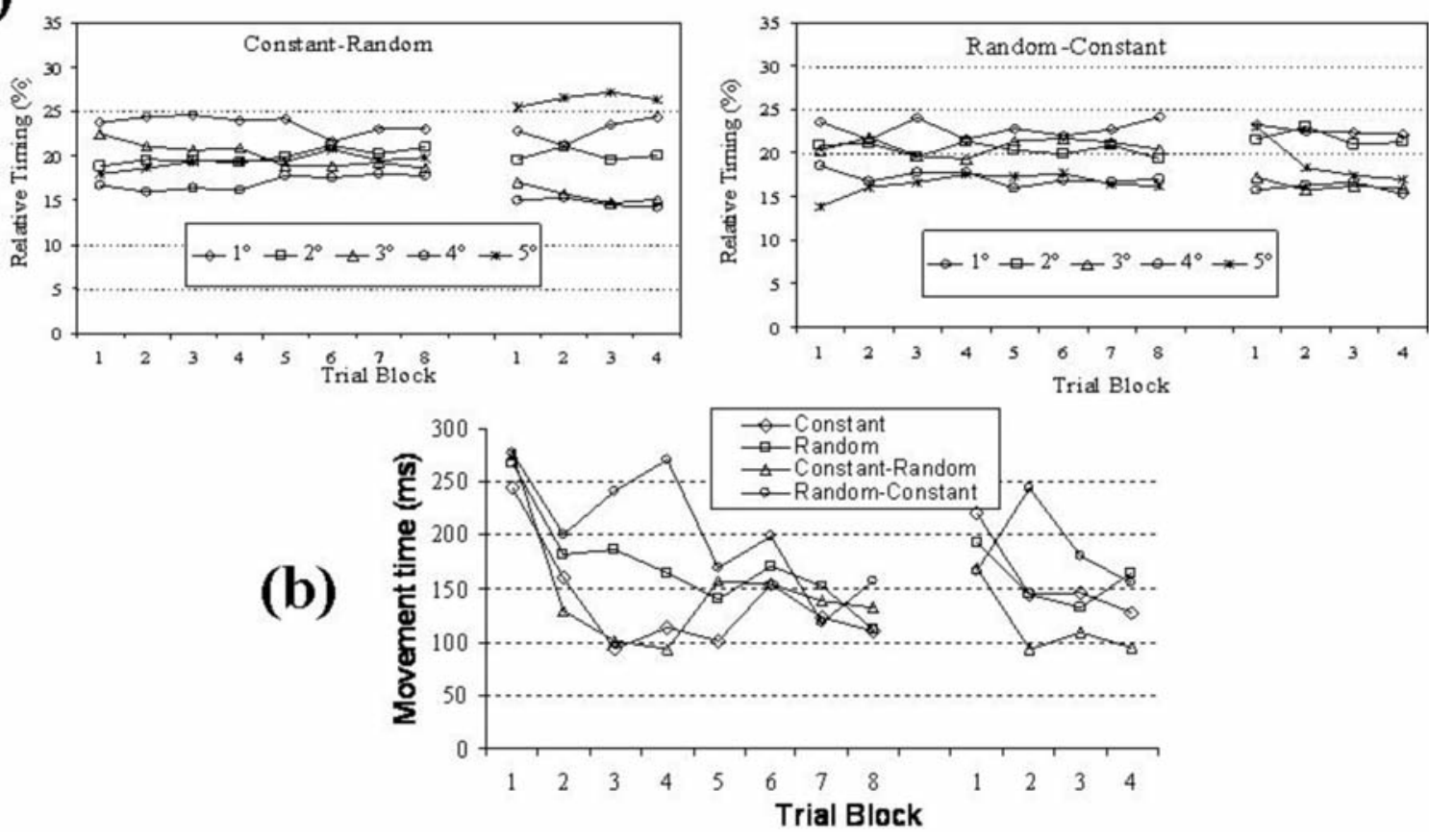

Figure 7. Movement pattern results in blocks of nine trials, in the stabilization (1 through 8) and adaptation (1 through 4] phases, Experiment 3: (a) mean of the magnitude of relative timing [\%] of each component $\left[1^{\circ}, 2^{\circ}, 3^{\circ}, 4^{\circ}\right.$, and $\left.5^{\circ}\right)$; (b) mean of variability of movement time (ms).

Concerning movement time, only the constant group: $\mathrm{F}_{7,88}=3.35, \mathrm{p}<0.01$, and the constant-random groups: $\mathrm{F}_{7,88}=3.93, \mathrm{p}<0.01$, showed a decrease in variability during the stabilization phase. With regard to the results of the adaptation phase, the two-way ANOVA detected differences for blocks: $\mathrm{F}_{4,172}=4.33, \mathrm{p}<0.01$. The TukeyHSD test indicated that the movement time variability increased significantly when the task was modified; and, also decreased in the next blocks. The ANOVA also found interaction: $F_{12,172}=1.92$, $\mathrm{p}<0.05$. Nevertheless, the TukeyHSD post-hoc test was not able to identify such differences.

\section{DISCUSSION}

These results showed that the constant-random practice group obtained better performance (absolute and variable errors) than did the random-constant group. In terms of movement pattern (relative timing), it was observed that the constant practice group modified three components ( 1 st, $3^{\text {rd }}$, and $\left.5^{\text {th }}\right)$; the random practice group also modified three components ( $3^{\text {rd, }}$ $4^{\text {th }}$, and $5^{\text {th }}$ ); the constant-random practice group modified two components ( $4^{\text {th }}$ and $5^{\text {th }}$ ); and, finally, the random-constant practice group modified the magnitude of three components (2nd, $3^{\text {rd }}$ and $\left.5^{\text {th }}\right)$. In 
short, the constant-random group was the group that least modified its movement pattern in terms of invariant structure. It could be erroneously assumed that the modification of three components could be related to flexibility. However, to the contrary, the results of absolute error lead us to suggest that this is not the case. With regard to the variant structure of the movement pattern, we concluded that the constant-random practice group obtained a more consistent movement time than did the random-constant group, perhaps because the constant-random group was less disturbed by task modifications. It's interesting to note that all groups modified the $5^{\text {th }}$ component. This probably occurred due to the last touch to be responsible for final adjustments.

\section{GENERAL DISCUSSION}

In general, the results of the current study suggest that there is greater adaptation during motor skill acquisition with constant practice alone, and, also, when allied with random practice. Specifically, in Experiment 1, the results supported the superiority of constant, constant-random, and random-constant practice. Experiment 2 helped to verify the superiority of constant and constant-random practice; and, the findings in Experiment 3 supported the superiority of constant-random practice.

However, why does constant practice, combined with random practice, contribute more than does only random practice to the formation of a more flexible structure? It is important to emphasize that Corrêa et al.(13) have suggested that variable practice may be deleterious to learning if some degree of stability was not yet achieved. It seems that a system cannot adapt itself if it is still in an unstable state. This does not mean that variable practice cannot be advantageous, because the results obtained by constant-random practice group are suggesting in that sense.

It can be assumed that, when the characteristics of a particular type of constant practice are presented, the formation of an interaction pattern between the components occurs. Additionally, given the results of the constant-random and random-constant practices in Experiment 1, one might assume that the quantity of constant practice in each of these two groups was sufficient for the formation of a skill with a structure that was flexible enough for adaptation.
That is, adaptation to a new situation may have depended on the redundancy achieved by the system during the stabilization phase(13) rather than on the generalization of rules allowed by randomly varied practice. Redundancy during the motor learning process can be thought of as an abundance of resources (flexibility) $(13,38)$.

A hierarchy can be used to help explain the results in the three experiments above, with respect to the requirements, or difficulty level, of the task modifications, including: perceptual (Experiment 1), spatial (Experiment 2), and perceptual and spatial aspects in conjunction with each other (Experiment 3 ), thus supporting Tani's findings(36). Tani(36) concluded that, when modification of the task includes temporal and spatial aspects in conjunction with each other, there is a superior level of disturbance as compared to modifications of only spatial aspects. This, in turn, causes superior disturbances in comparison to the modification of only temporal aspects. In the current study, when the modification of the task included perceptual aspects, a superior adaptation in the three groups was observed (constant, random-constant and constant random). When modification occurred with regard to the touch sequence, a superior adaptation in two groups was observed (constant and constant-random). When the alteration of the task involved both aspects, the constantrandom group achieved the best performance.

In the latter case, how can constant practice, which includes information repetition, stability, consistency, order, precision, and random practice-which includes uncertainty, instability, inconsistency, disorder and error, both be integrated during the process of motor skill acquisition? A systemic framework can help to explain that, although constant practice enables the formation of an interaction pattern between skill components, the results of Experiment 3 might reflect an emphasis on a single interaction pattern. That is, perhaps only constant practice would not have caused sufficient redundancy for adaptation. The results also allowed us to conclude that random practice did not enable sufficient interaction amongst the practiced motor skill components for the formation of a consistent structure. Therefore, the results for the constant-random group allow us to conclude that, after the pattern of inter- 
action between the system components was formed (constant practice), the introduction of variations in the components (random practice) increased the range of interactions without causing the pattern to lose its identity; or, rather, it maintained its identity. This increase in the quantity of motor behavioral elements, considered a fundamental process in the increase of complexity, has been labeled behavioral diversification $(14,35)$.

The process through which this process typically occurs is that, first, an interaction pattern between a system's components is formed, which is then followed by a diversification of this pattern. This phenomenon is illustrated in the results of the randomconstant practice group, whose poorest performance occurred in Experiments 2 and 3. The constant-random practice group seemed to have benefited most from diversification during motor skill acquisition since it achieved the highest level of performance of the three experiments.

In general, in terms of motor skills acquisition, constant practice can enable enough availability of resources for a system to adapt to certain situations. However, some disturbances require constant practice in order to form the structure of a particular skill, and, subsequently, random practice in order to promote diversity, which enables flexibility(14). In other words, it is possible to imagine that constant and constant-random practices during the stabilization process may lead the system to an optimal level of adaptation. According to Choshi and Tani $(7,8,36,37,38)$, the adaptive process in motor learning has stabilization as a prerequisite. In fact, one of the possible conditions in order for adaptation to occur during a disturbance may be the organization of the critical state

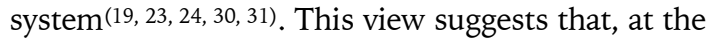
limit of chaos, when the organization of a system lies between order and disorder, it presents consistency and a high degree of flexibility, simultaneously; and it is able to maintain its pattern or adapt itself to the disturbances through a qualitative leap $(19,21,23,24,25,30)$. It might be also possible to imagine, then, that since a human is incapable of executing two identical movements, no single solution to a given motor problem is the most efficient; that, rather, a group of appropriate solutions typically solves the problem. It seems reasonable to assume, then, that constant practice enables the achievement of stability within an array of appropriate solutions for a given problem, and that when random practice is conducted after constant practice, the size of the group of solutions increases, thus allowing for even more possibilities. Explanations regarding the efficacy of different practice structures on the acquisition of motor skills have typically included such components as generalized motor programs, schemes, traits, and action plans, as well as representations of the central nervous system, in order to identify what is "acquired" with practice. Yet, these approaches are inherently limited in their ability to explain certain motor behavioral phenomena, including some of the results found in the current study. Hence, the authors propose a new explanation, inspired by these limitations, which includes an action program with the characteristics of an open system, organized at macro- and microscopic hierarchal levels, which contemplate invariant and variant aspects $(17,27,38)$. According to this proposal, the macrostructure of an action program refers to its general pattern, which emerges from the interaction of components, and which is guided by order and is responsible for the consistency of skillful actions. The microstructure itself corresponds to its own components. It is guided by disorder, and, thus, is the origin of the variability of the skillful actions.

In conclusion, the results of the present study point to the positive effects of constant practice, alone and in conjunction with random practice, on the adaptive process of motor learning. These results, as well as their possible explanations, suggest the development of an alternative motor learning model. However, as with all model and theory development, such results need to be replicated in order to confer the necessary consistency. Yet, the results of our experiments suggest that the future is ripe for studies that examine motor skill learning as a continuous process that involves cycles of stabilization and adaptation; or, rather, that the study of motor skill learning requires the development of a non-equilibrium model.

\section{CORRESPONDENCE}

\section{Umberto Cesar Corrêa}

Escola de Educação Física e Esporte - USP

Av. Prof. Mello Morais, 65 - São Paulo - SP, CEP

05508-030 - Brazil

E-mail: umbertoc@usp.br 


\section{REFERENCES}

1. Adams JA (1971). A closed-loop theory of motor learning. Journal of Motor Behavior, 3: 111-150

2. Annett J (1985). Motor learning: a review. In H Heuer, U Klewbeck, \& KH Schmidt. (Eds.), Motor behavior: programming, control, and acquisition. Berlin, Springer-Verlag, 189-92

3. Bard C, Fleury M, Gagnon M (1990). Coincidence-anticipation timing: an age related perspective. In: C Bard, M Fleury, \& L Hay (Eds.), Development of eye-hand coordination across life span. Columbia: University of South Carolina, 283-305

4. von Bertalanffy L (1977). Teoria geral dos sistemas. (2th ed.). Petrópolis: Vozes

5. Brady F (1998). A theoretical and empirical review of the contextual interference effect and the learning of motor skills. Quest, 50: 266-93

6. Choshi K (1985). Adaptive process of perceptual-motor learning: complexity and complementarity. Memoirs of the Faculty of Integrated Arts and Sciences VI. Hiroshima University, 3: 21-30. (In Japanese)

7. Choshi K (2000). Aprendizagem motora como um problema mal-definido. Revista Paulista de Educação Física, 3: 17-23

8. Choshi K, Tani G (1983). Stable system and adaptive system in motor learning. In Japanese Association of Biomechanics (Ed.), The science of movement $V$. Tokio: Kiorin, 346-51. (in Japanese)

9. Connolly KJ (1975). Movement, action and skill. In: Holt, KS (ed.), Movement and child development. London, Academic Press, 102-10.

10. Cook ND (1980). Stability and flexibility: an analysis of natural systems. Oxford: Pergamon Press

11. Cormier SM, Hagman JD (1987). Transfer of learning: contemporary research and applications. San Diego, California: Academic Press

12. Corrêa UC, Benda RN, Tani G (2001). Estrutura de prática e processo adaptativo na aprendizagem do arremesso de dardo de salão. Revista Brasileira de Ciências do Esporte, 22: 69-84

13. Corrêa UC, Benda RN, Meira Junior CM, Tani G (2003). Practice schedule and adaptive process in the acquisition of a manual force control task. Journal of Human Movement Studies, 44: 121-138

14. Corrêa UC, Barros JAC, Gonçalves LA, Massigli M, Souza Jr. O (2004). Constant-random practice and adaptive process in motor learning: effect of different quantities of constant practice on motor skill acquisition. Journal of Sport \& Exercise Psychology, 26 (Suppl.): S59

15. Fischman MG, Christina RW, Vercruyssen MJ (1982). Retention and transfer of motor skills: a review for the practitioner. Quest, 33: 181-94

16. Ford DH, Lerner RM (1992). Developmental systems theory: an introduction approach. Newburypark: Sage

17. Freudenheim AF, Manoel EJ (1999). Organização hierárquica e a estabilização de um programa de ação: um estudo exploratório. Revista Paulista de Educação Física, 13: 177-96

18. Ingvaldsen RP, Whiting HTA (1997). Moderns views on motor skill learning are not 'representative'! Human Movement Science, 16: 705-732.
19. Kauffman SA (1991). Antichaos and adaptation. Scientific American, 265: 64-70

20. Kelso JAS (1995). Dynamic patterns: the self-organization of brain and behavior. Cambridge, Massachusetts: The MIT Press

21. Kelso JAS, Haken H (1997). Novas leis antecipáveis no organismo: a sinergética do cérebro e do comportamento. In MP Murphy, \& LAJ O’Neill (Eds.), “O que é vida?” 50 anos depois: especulações sobre o futuro da biologia. São Paulo: Editora da UNESP, 159-185

22. Lai Q, Shea CH, Wulf G, Wright DL (2000). Optimizing generalized motor program and parameter learning. Research Quarterly for Exercise and Sport, 71: 10-24

23. Langton CG (1992). Life at the edge of chaos. In CG Langton, C Taylor, JD Farmer \& S Rasmussen (Eds.), Artificial life II: SFI studies in the sciences of complexity V. Redwood City: Addison-Wesley, 41-92.

24. Lewin R (1994). Complexidade: a vida no limite do caos. Rio de Janeiro: Rocco.

25. Lorenz E (1996). A essência do caos. Brasília: Editora da UnB.

26. Magill RA, Hall KG (1990). A review of the contextual interference effect in motor skill acquisition. Human Movement Science, 9: 241-89

27. Manoel EJ, Basso L, Corrêa U, Tani G (2002). Modularity and hierarchical organization of action programs in the acquisition of graphic skills. Neuroscience Letters, 335: 8386.

28. Newell KM (1989). On task and theory specificity. Journal of Motor Behavior, 21: 92-6.

29. Newell KM (1991). Motor skill acquisition. Annual Review in Psychology, 42: 213-237

30. Packard NH (1988). Adaptation toward the edge of chaos. In JAS Kelso, AJ Mandel \& MF Shlesinger (Eds.), Dynamic patterns in complex systems. Singapore: World Scientific Publishing, 293-301

31. Prigogine I, Stengers I (1984). A nova aliança: metamorfose da ciência. Brasília: Editora da Universidade de Brasília.

32. Schmidt RA (1975). A schema theory of discrete motor skill learning. Psychological Review, 82: 225-60.

33. Schmidt RA, Lee TD (1998). Motor control and learning: $a$ behavioral emphasis. ( $3^{\text {rd }}$ ed.), Champaign, Human Kinetics

34. Singer RN (1980). Motor Performance and human performance: an application to motor skills and movement behaviors. ( $3^{\mathrm{a}}$ ed.). New York: Macmillan Publishing Co., Inc.

35. Tani, G (1987). Educação Física na pré-escola e nas quatro primeiras séries do ensino de primeiro grau: uma abordagem desenvolvimentista I. Kinesis, 3: 19-41

36. Tani G (1995). Hierarchical organisation of human motor behaviour. Sheffield, University of Sheffield, (Unpublished Technical Report).

37. Tani G (2000). Processo adaptativo em aprendizagem motora: o papel da variabilidade. Revista Paulista de Educação Física, 3: 55-61

38. Tani G (2005). Processo adaptativo: uma concepção de aprendizagem motora além da estabilização. In: Tani, G (Ed.), Comportamento Motor: Desenvolvimento e Aprendizagem. Rio de Janeiro: Guanabara Koogan, p.60-70 